Article

\title{
Preparation of N-Doped Carbon Nanosheets from Sewage Sludge for Adsorption Studies of Cr(VI) from Aqueous Solution
}

\author{
Yi Wang ${ }^{1,+}$, Weinan Zhao ${ }^{1,+}$, Wanlan Zheng ${ }^{1}$, Shuang Chen ${ }^{1, *}$ and Jinsheng Zhao ${ }^{2, *} \mathbb{C}$ \\ 1 State Key Laboratory of Heavy Oil Processing, College of Chemical Engineering, China University of \\ Petroleum (East China), Qingdao 266580, China; wangiiupc@163.com (Y.W.); \\ zhaoweinan65@gmail.com (W.Z.); zhengyouxi-1@163.com (W.Z.) \\ 2 Shandong Key Laboratory of Chemical Energy Storage and Novel Cell Technology, Liaocheng University, \\ Liaocheng 252059, China \\ * Correspondence: chsh1030@163.com (S.C.); j.s.zhao@163.com (J.Z.) \\ + These authors contributed equally to this work.
}

Received: 21 January 2019; Accepted: 12 February 2019; Published: 15 February 2019

check for updates

\begin{abstract}
Porous activated carbon with specific morphology and structure are of particular importance for waste water treatment, especially for the adsorption of toxic hexavalent chromium $\mathrm{Cr}(\mathrm{VI})$. However, the scalable and cheap production of such absorbents still suffer a grand challenge. Herein, a new type of $\mathrm{N}$-doped nanosheet was innovatively prepared from easily available and low-cost sewage sludge via a facile and recyclable $\mathrm{KOH}$ activation method. The $\mathrm{N}$-doped porous carbon nanosheets (N-SAC) produced by introduction of $\mathrm{KOH}$ and dicyandiamide, which performed favourable features for metal ions adsorption $(93.2 \%$ for $\mathrm{Cr}(\mathrm{VI}))$ due to its high specific surface area, tuneable pore size distributions and good hydrophilicity. Additionally, the capacity also remained high after two cycles of adsorption by thermal regeneration, with $90.8 \%$ removal rate. The DFT calculation also approved that the doping of $\mathrm{N}$ could optimize the Mulliken charges distribution and improve the HOMO energy and improve the adsorption ability of N-SAC. This original proposal may inspire new possibility of creating porous carbon absorbents in a recyclable method.
\end{abstract}

Keywords: sewage sludge; nitrogen-doped carbon nanosheets; $\mathrm{Cr}(\mathrm{VI})$ adsorption; recycled materials; DFT calculation

\section{Introduction}

Water pollution, arising from the discharge of sewage, is imposed as a serious threat to ecological balance in the environment [1,2]. The accumulation of organic micropollutants, highly toxic substances, such as heavy metals, PAHs or pesticides, were found in water and it became one of the biggest challenges to public health and ecosystems today. Thus, removing these contaminants more effective by using efficient and cheap materials is highly desired.

Poisonous metal ions $[3,4]$ is the most dangerous contaminant due to its high carcinogenicity and teratogenicity that cannot be decomposed. And Chromium, a typical heavy metals containment, which mainly existing in two state: $\mathrm{Cr}(\mathrm{III})$ and $\mathrm{Cr}(\mathrm{VI})$ in the natural environment. $\mathrm{Cr}(\mathrm{III})$ is recognized as a micro nutrient for human requirement at a low concentration, whereas $\mathrm{Cr}(\mathrm{VI})$, from industry effluents, only presents a poisonous performance after accumulating in human system which could have an adverse effect on people's blood [5-7], bone and nerve transmission. Therefore, it is highly required to remove $\mathrm{Cr}(\mathrm{VI})$ from waste water. There are various advanced treatments to reduce the harmfulness of $\mathrm{Cr}(\mathrm{VI})$ discharge, such as chemical precipitation, bio flocculation, adsorption, membrane separation and so forth. But the most practical and effective approach is adsorption that 
based on absorbents, such as activated carbon. While activated carbon is expensive non-recyclable and needs proper condition of use, the further application and utilization of adsorption method is limited for waste water treatment.

From a sustainable viewpoint, the seeking for renewable carbon source is of critical importance in bringing carbon-based absorbents into practical waste water treatment [8,9]. However, some useful strategies developed so far for improving the adsorption capacity from naturally abundant biomass, including cellulose, hemicelluloses and lignin which represents the most promising precursor for sustainable activated carbon production $[10,11]$. The high price and low utilization still cannot implement recycle and reuse [7]. On the other hand, the cheap biomass, such as chicken eggshell, prawn shells, soybeans, human hair, garlic skin and ant powder [12-15], have also been extensively investigated as raw materials for carbon materials. But it was constrained by its low adsorption efficiency and complicated synthesis process.

Sewage sludge, as a kind of hard-to-dispose yet rich organic matters [16-18], has been used mainly in landfills or directly burned [19]. It will also cause great waste of resources and damage on the environment. Taking account of high contents of aromatic and high carbon yield in sewage sludge, it is necessary to utilize its available advantages to fabricate high-value-add carbon adsorbent towards waste water pollution.

Herein, we demonstrated a facile and recyclable method to synthesize nitrogen-doped porous carbon nanosheets (N-SAC) via sewage sludge through a mildly modified $\mathrm{KOH}$ activation process [20]. Under $\mathrm{KOH}$ activation process, the biomass can be converted into carbon material with large specific surface area and large porosity and the adding of dicyandiamide served as soft template to form the nanosheets morphology. Due to these structural and morphological merits, the N-SAC has achieved a high adsorption performance of $\mathrm{Cr}(\mathrm{VI})$ in a wide $\mathrm{pH}$ range (93.2\%). And successful regeneration process also demonstrated the high utilization of N-SAC. Besides, the DFT calculation explored the mechanism of high performance of adsorption via Mulliken charges distribution, HOMO energy and adsorption energy. It is not only can fabricate carbon adsorbents by a facile and recyclable way but also provides a new possibility for synergistic treatment of sewage and sludge.

\section{Materials and Methods}

\subsection{Materials Synthesis}

Sewage Sludge (SS) were obtained from a waste water plant in Dong Ying, northeast of China. $\mathrm{KOH}$ and dicyandiamide was bought from Aladdin Ltd. Distilled water was used throughout the experiments. All other chemicals were of analytical grade and used without any further purification process.

Preparation of sewage sludge carbon (SSC): The sewage sludge was derived from wastewater treatment plant. Firstly, the sewage sludge was washed by distilled water and ethanol to remove dust and other inorganic impurities and then dried at $60{ }^{\circ} \mathrm{C}$ for $24 \mathrm{~h}$. After that, it was ground and screened from 40 to 100 mesh to filtrate the appropriate size that stored for further studies. The contents of moisture, volatile material, ash and fixed carbon of SS were determined according to national standard (GB/T 12496.3-1999) [21]. Then, amount of $5.0 \mathrm{~g}$ of the SS material was introduced into porcelain crucible, which was heated in tubular reheating furnace applying a temperature program of pre-carbonized at $550{ }^{\circ} \mathrm{C}$ for $1 \mathrm{~h}$ under nitrogen atmosphere which named sewage sludge carbon (SSC).

Preparation of SAC and N-SAC: The sludge-based activated carbon (SAC) and N-doped sludge-based activated carbon (N-SAC) were prepared from a step of balling with SSC and $\mathrm{KOH}$ and dicyandiamide at the mass ratio (1:3:0, 1:3:1). Then the mixtures were heated to $800{ }^{\circ} \mathrm{C}$ for $2 \mathrm{~h}$ at a heating rate of $5^{\circ} \mathrm{C} \min ^{-1}$ in $\mathrm{N}_{2}$ atmosphere. Finally, the carbon materials were collected through repeated washing with the dilute $\mathrm{HCl}$ solution $(2 \mathrm{M})$ and distilled water for $10 \mathrm{~h}$ and then dried at $105^{\circ} \mathrm{C}$ overnight. After cooling down to room temperature, SAC and N-SAC were obtained. 
Preparation of N-SAC': The adsorbed N-SAC was centrifuged from solution and calcined at $800{ }^{\circ} \mathrm{C}$ for $2 \mathrm{~h}$ with a heating rate of $5^{\circ} \mathrm{C} \mathrm{min}^{-1}$ in $\mathrm{N}_{2}$ atmosphere to regenerate the adsorbent. And then the products were gathered by repeated washing with high concentration of potassium hydroxide and distilled water. After dried at $105^{\circ} \mathrm{C}, \mathrm{N}-\mathrm{SAC}$ ' were obtained.

\subsection{Adsorption Characterization}

For the adsorption studies, a stock solution of $100 \mathrm{mg} \cdot \mathrm{L}^{-1}$ was prepared by dissolving $50 \mathrm{mg}$ of $\mathrm{K}_{2} \mathrm{Cr}_{2} \mathrm{O}_{7}$ in $1000 \mathrm{~mL}$ of deionized water. The working solutions were prepared by diluting of the stock solution and the $\mathrm{PH}$ adjusted with $\mathrm{HCl}\left(0.1 \mathrm{~mol} \cdot \mathrm{L}^{-1}\right)$ and $\mathrm{NaOH}\left(0.1 \mathrm{~mol} \cdot \mathrm{L}^{-1}\right)$ solutions.

The $\mathrm{pH}$ effect was evaluated by $50.0 \mathrm{~mL}$ of $\mathrm{Cr}(\mathrm{VI})$ solution with initial concentration of $10 \mathrm{mg} \cdot \mathrm{L}^{-1}$ and $\mathrm{pH}$ ranging from 2.0 to 8.0. Aliquots were placed in contact with $0.1 \mathrm{~g}$ of N-SAC and shaken by $2 \mathrm{~h}$ in a shaker incubator at $25^{\circ} \mathrm{C}$. Then, $\mathrm{Cr}(\mathrm{VI})$ remaining concentrations were determined by a HASH water quality analyser (DR2800, U.S.A). The maximum amount adsorbed ( $\left.\mathrm{q}_{\mathrm{m}}\right)$ was calculated by Equation (1) [22]:

$$
\mathrm{q}_{\mathrm{m}}=\left[\left(\mathrm{C}_{0}-\mathrm{C}_{\mathrm{r}}\right) / \mathrm{V}\right] / \mathrm{m}
$$

where $C_{0}$ and $C_{r}$ are initial and final concentrations of $\mathrm{Cr}(\mathrm{VI})\left(\mathrm{mg} \cdot \mathrm{L}^{-1}\right)$, respectively, $\mathrm{V}$ is the solution volume $(\mathrm{L})$ and $\mathrm{m}$ is the mass of $\mathrm{N}-\mathrm{SAC}(\mathrm{g})$.

The experiments of adsorption kinetics were performed from the mechanical stirring in time intervals ranging from 5 to $120 \mathrm{~min}$, using a shaker incubator. Aliquots of $50.0 \mathrm{~mL}$ of $\mathrm{Cr}(\mathrm{VI})$ solutions with concentrations of 5.0, 10.0 and $15.0 \mathrm{mg} \cdot \mathrm{L}^{-1}(\mathrm{pH}=6.0)$ were placed in contact with $0.1 \mathrm{~g}$ of N-SAC. After stirring, $\mathrm{Cr}(\mathrm{VI})$ remaining concentrations were determined. The amount of $\mathrm{Cr}(\mathrm{VI})$ adsorbed at time $\mathrm{t}\left(\mathrm{q}_{\mathrm{t}}\right)$ [23] were calculated using Equation (2):

$$
\mathrm{q}_{\mathrm{t}}=\left[\left(\mathrm{C}_{0}-\mathrm{C}_{\mathrm{t}}\right) / \mathrm{V}\right] / \mathrm{m}
$$

where $C_{0}$ and $C_{t}$ are initial and final concentrations of $\mathrm{Cr}(\mathrm{VI})\left(\mathrm{mg} \cdot \mathrm{L}^{-1}\right)$, respectively, $\mathrm{V}$ is the solution volume $(\mathrm{L})$ and $\mathrm{m}$ is the mass of $\mathrm{N}-\mathrm{SAC}(\mathrm{g})$.

Non-linear equations of kinetic models of pseudo-first-order and pseudo-second-order and isotherm models of Langmuir and Freundlich were fitted to the experimental data, to assess the dynamics and adsorption capacity. The model fits were evaluated from the normalized standard determination coefficients $\left(\mathrm{R}^{2}\right)$.

Internal diffusion model (IPD) was used to explain the adsorption mechanism and determine the rate control steps in the adsorption process. IPD model was calculated using Weber-Morris formula as follow Equation (3) [24]:

$$
Q_{\mathrm{t}}=K_{\mathrm{id}} \mathrm{t}^{(1 / 2)}+k_{0}
$$

where $Q_{t}$ is the equilibrium adsorption capacity of $\mathrm{Cr}(\mathrm{VI})\left(\mathrm{mg} \cdot \mathrm{g}^{-1}\right)$, respectively, $K_{\mathrm{id}}$ is the internal diffusion rate constant, $\mathrm{k}_{0}$ is a constant.

The effect of temperature in the $\mathrm{Cr}(\mathrm{VI})$ adsorption onto $\mathrm{N}-\mathrm{SAC}$ was evaluated from thermodynamic studies. Aliquots of $50.0 \mathrm{~mL}$ of $\mathrm{Cr}(\mathrm{VI})$ solution of $10.0 \mathrm{mg} \cdot \mathrm{L}^{-1}(\mathrm{pH}=6.0)$ were placed in contact with $0.1 \mathrm{~g}$ of N-SAC, in polypropylene flasks and stirred for $6 \mathrm{~h}$ using a shaker incubator at temperature of $15,25,35,45,55^{\circ} \mathrm{C}$. After the equilibrium time, the remaining $\mathrm{Cr}(\mathrm{VI})$ concentrations were determined and the adsorbed maximum amount calculated from Equation (2). The thermodynamic parameters, such as Gibbs free energy $\left(\Delta \mathrm{G}^{0}\right)$, enthalpy change $\left(\Delta \mathrm{H}^{0}\right)$ and entropy change $\left(\Delta S^{0}\right)$ were calculated from the equations (Equations (4)-(6)).

$$
\begin{gathered}
\mathrm{K}_{\mathrm{d}}=\mathrm{q}_{\mathrm{m}} / \mathrm{c}_{\mathrm{m}} \\
\ln K_{d}=\frac{\Delta S^{0}}{R}-\frac{\Delta H^{0}}{R T} \\
\Delta G^{0}=\Delta H^{0}-T \Delta S^{0}
\end{gathered}
$$


where $K_{d}$ is the distribution coefficient, $R=8.314 \mathrm{~J} \cdot \mathrm{mol}^{-1} \cdot \mathrm{K}^{-1}$ is the constant, $\mathrm{T}(\mathrm{K})$ is the adsorption temperature.

\subsection{Density Functional Theory (DFT)}

DFT calculation: has been carried out to investigate the effect of $\mathrm{N}$ doped active sites of adsorbents on $\mathrm{Cr}(\mathrm{VI})$ removal. All the calculations have employed the Gaussian 09 program. The B3LYP / 6-31G+ (d,p) level functional was used to calculate adsorption energies and were corrected by BSSE. The adsorption energy $\left(E_{\mathrm{ad}}\right)$ of the adsorbate was defined as the equation:

$$
E(\mathrm{ad})=E\left(\text { structure }+\mathrm{HCrO}_{4}^{-}\right)-E(\text { structure })-E\left(\mathrm{HCrO}_{4}^{-}\right)+E(\mathrm{BSSE})
$$

\section{Results and Discussion}

\subsection{Proximate Analysis and Yield of Activated Carbon (SAC, N-SAC)}

The contents of moisture, volatile material, ash and fixed carbon of sewage sludge were measured and obtained as $4.93 \%, 35.80 \%, 14.35 \%$ and $44.92 \%$, respectively. According to results, the sewage sludge has sufficient amount of organic matter which represented by the percentage of fixed carbon content. In the meantime, the content of ash in this sludge could provide a possibility for preparing activated carbon during high temperature calcination and acquire excellent adsorption capacity.

The preparation process of N-SAC was shown in Scheme 1. Firstly, the sewage sludge carbon (SSC) was mixed with $\mathrm{KOH}$ and dicyandiamide. Then these mixtures were balled milling for $8 \mathrm{~h}$ until blended completely and be calcined in $\mathrm{N}_{2}$ atmosphere. When the mixtures were heated approximately $550{ }^{\circ} \mathrm{C}$, dicyandiamide was polymerized and generated $\mathrm{g}-\mathrm{C}_{3} \mathrm{~N}_{4}$ inside the SSC layer and the two-dimensional morphology of $\mathrm{g}-\mathrm{C}_{3} \mathrm{~N}_{4}$ carbon nanosheets could act as a soft template to guide and limit space of carbon mixture. Subsequently, when the annealing temperature was up to $800{ }^{\circ} \mathrm{C}$, the decomposition of $g-\mathrm{C}_{3} \mathrm{~N}_{4}$ could release gaseous nitrogen sources to dope into the carbon framework and produce the carbon nanosheets after all the $\mathrm{g}-\mathrm{C}_{3} \mathrm{~N}_{4}$ evaporation [11]. It is worth nothing that $\mathrm{KOH}$ could be easily recovered and reused to the next production of carbon nanosheets. The SAC were prepared according the same procedure except adding of dicyandiamide. Finally, the yields of SAC, N-SAC were as high as $54.3 \%$ and $56.1 \%$, respectively and almost half weight loss could be assigned to the evaporation of volatile materials and ash from crude products. And the little higher yields of N-SAC compared with SAC due to the sufficient doped of nitrogen.

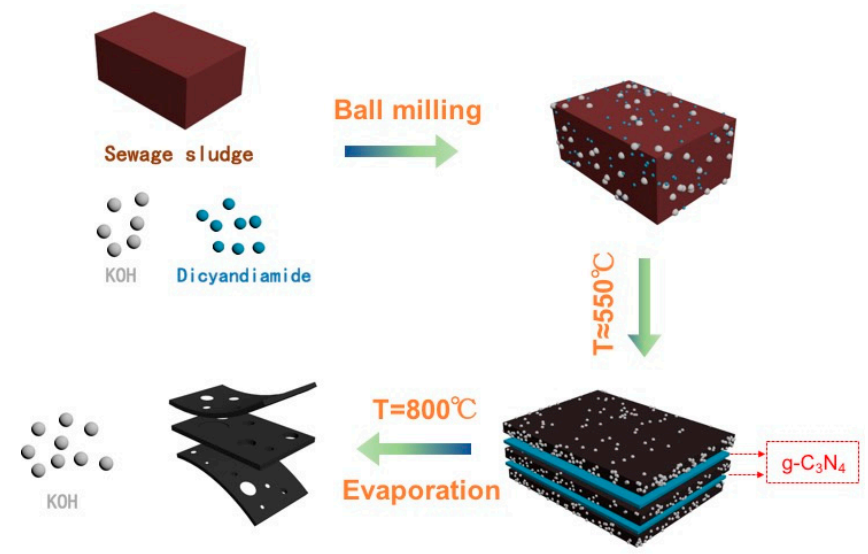

Scheme 1. Illustration of the preparation procedure for the N-SAC nanosheets in recycled malt system. 


\subsection{Characterization}

\subsubsection{Textural Properties}

The textural properties of the SAC and N-SAC were evaluated from the $\mathrm{N}_{2}$ adsorption/desorption isotherms and Brunauer-Emmett-Teller (BET).

The shape of the isotherm is related to type of solid porosity [25]. As shown in Figure 1a,b, the isotherms of SAC and N-SAC can be classified as type IV and hysteresis H4, presenting a rapid adsorption of $\mathrm{N}_{2}$ at low relative pressures and characteristic of microporous. The adsorption hysteresis loop appeared in medium relative pressure, which associated with capillary condensation that occurs in the mesoporous pores. Additionally, the narrow distribution of pore diameters for the SAC and N-SAC were calculated by DFT method in Figure 1c,d. As can be seen, the volumes of micropores (pore diameter $<2 \mathrm{~nm}$ ) for SAC and N-SAC were similar, indicating that the chemical activation of $\mathrm{KOH}$ could react with active carbon framework during high temperature treatment, which gradually etched and generated the well-defined microporous framework. In addition, the volume of mesopores (pore diameter 2 to $50 \mathrm{~nm}$ ) in N-SAC were much higher than SAC which could be attributed to the evaporation and decomposition of dicyandiamide during high temperature [21].
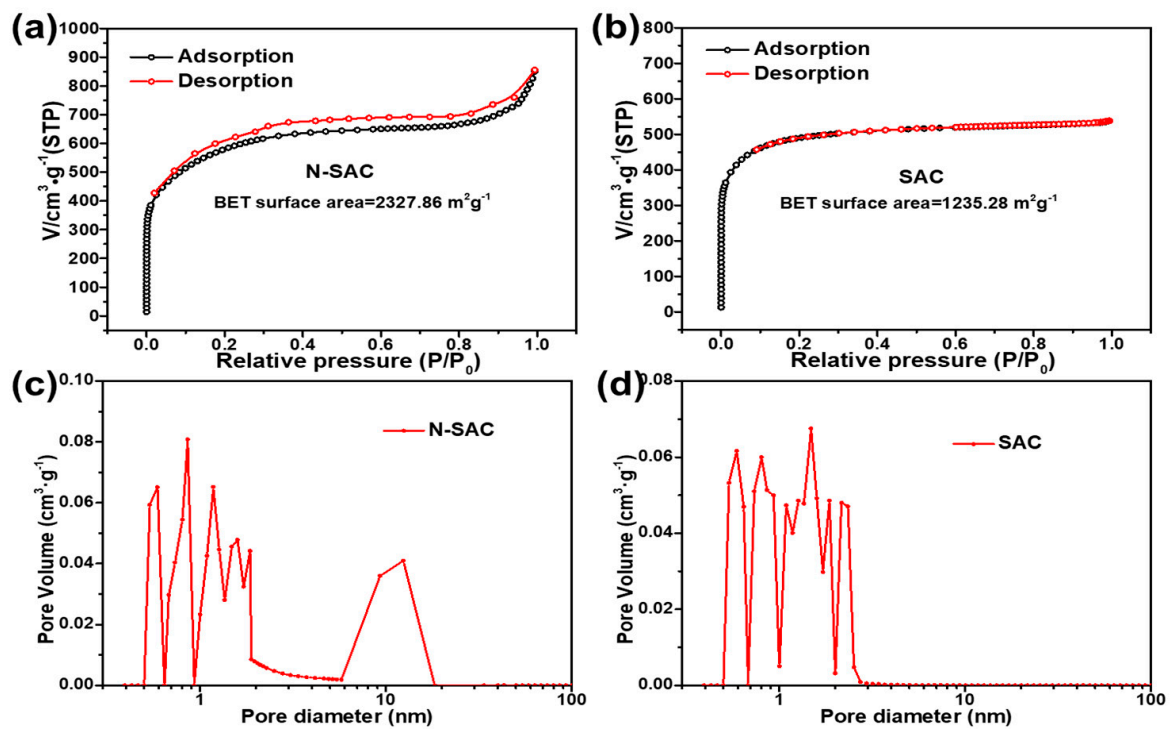

Figure 1. $\mathrm{N}_{2}$ adsorption-desorption isotherms and pore distribution calculated by DFT method for $(\mathbf{a}, \mathbf{c}) \mathrm{N}-\mathrm{SAC} ;(\mathbf{b}, \mathbf{d}) \mathrm{SAC}$.

The textural properties of SAC and N-SAC were also displayed in Table 1. As can be observed, a significantly increase of $D_{a p}$ value from $1.62 \mathrm{~nm}$ (SAC) to $5.50 \mathrm{~nm}(\mathrm{~N}-\mathrm{SAC})$, possibly driven by the reaction between $\mathrm{CO}_{2}$ and carbon, evaporating volatiles and increasing the pore sizes. Besides, SAC and N-SAC showed specific surface area (S $\mathrm{BET}$ ) of $1235.2 \mathrm{~m}^{2} \mathrm{~g}^{-1}, 2327.8 \mathrm{~m}^{2} \mathrm{~g}^{-1}$ respectively, which reached in this study are higher than other activated carbon (ACs) reported in literature $[26,27]$ used sewage sludge as precursor. As a result, these merits of N-SAC could increase the contact area between adsorbent and waste water and expose more active sites for adsorbing $\mathrm{Cr}(\mathrm{VI})$ in solution.

Table 1. Textural information of SAC and N-SAC.

\begin{tabular}{ccccccc}
\hline Sample & $\begin{array}{c}\mathbf{D}_{\mathrm{ap}} \\
(\mathbf{n m})\end{array}$ & $\begin{array}{c}\mathbf{S}_{\mathrm{BET}} \\
\left(\mathbf{m}^{\mathbf{2}} \mathbf{g}^{-\mathbf{1}} \mathbf{)}\right.\end{array}$ & $\begin{array}{c}\mathbf{S}_{\text {mic }} \\
\left(\mathbf{m}^{\mathbf{2}} \mathbf{g}^{-\mathbf{1}}\right)\end{array}$ & $\mathbf{V}_{\mathbf{t}}\left(\mathbf{c m}^{\mathbf{3}} \mathbf{g}^{-\mathbf{1}}\right)$ & $\begin{array}{c}\mathbf{V}_{\text {mic }} \\
\left(\mathbf{c m}^{\mathbf{3}} \mathbf{g}^{-\mathbf{1}}\right)\end{array}$ & $\mathbf{V}_{\text {mic }} / \mathbf{V}_{\mathbf{t}} \mathbf{( \% )}$ \\
\hline N-SAC & 5.50 & 2327.8 & 1736.1 & 1.35 & 0.97 & 71.8 \\
SAC & 1.62 & 1235.2 & 1126.2 & 0.62 & 0.59 & 95.1 \\
\hline
\end{tabular}

Dap-average pore diameter; $\mathrm{S}_{\mathrm{BET}}-\mathrm{BET}$ surface area; $\mathrm{V}_{\mathrm{T}}$-total pore volume; $\mathrm{V}_{\text {mic }}$-micropore volume; $\mathrm{V}_{\mathrm{mic}} / \mathrm{V}_{\mathrm{t}}$-micropore percentage. 


\subsubsection{Morphology Analysis}

The scanning electron micrograph (SEM) was carried out to evaluate the morphology of materials. As shown in Figure S1, it showed that raw materials, sewage sludge, have a compact structure without any cavities. After activated by $\mathrm{KOH}, \mathrm{SAC}$ (Figure S2) has the loose structure, where the surface of the carbon is decorated with macropores. However, after the adding of dicyandiamide and calcination, N-SAC showed more open frameworks and two dimensional carbon nanosheets with wrinkled surface. Herein, the modification of N-SAC by dicyandiamide played an important role for guiding and expanding space during high temperature treatment. Firstly, the molecular of dicyandiamide was inserted into carbon matrix of SAC during the ball-milling process. Then, $\mathrm{g}-\mathrm{C}_{3} \mathrm{~N}_{4}$ was formed as the pyrolysis products of dicyandiamide at $550{ }^{\circ} \mathrm{C}$ which possessed sheet-like morphology and served as a template guiding the SAC carbon framework. Next, g- $\mathrm{C}_{3} \mathrm{~N}_{4}$ were decomposition when the temperature is about $600{ }^{\circ} \mathrm{C}$ and reaction system has no residual g- $\mathrm{C}_{3} \mathrm{~N}_{4}$ after it completely decomposed at $800{ }^{\circ} \mathrm{C}$. These results were well in agreement with textural characteristics showed in Table 1, which surface area raised after modification, due to the activation and release of volatile compounds during carbonization process [12,28]. Moreover, the Transmission Electron Microscope (TEM) were test to verify the nanolattice structure. As shown in Figure 2c, the image exhibits the sheet-like structure which well match with SEM results. And in the high-resolution TEM (HR-TEM) picture, it could be observed that the surface of the nanosheets are full of micropores, which can secure large surface area and high porosity. Sewage sludge presents a dense surface without cavities, whereas SAC and N-SAC both show a rougher surface with cavities of various dimensions, indicating a well-developed porous structure especially on N-SAC. The pores on N-SAC surface provide suitable channels for the penetration of $\mathrm{Cr}(\mathrm{VI})$ ions into the carbon structure, allowing access to its mesopores and micropores, where they can interact with the surface functional groups.

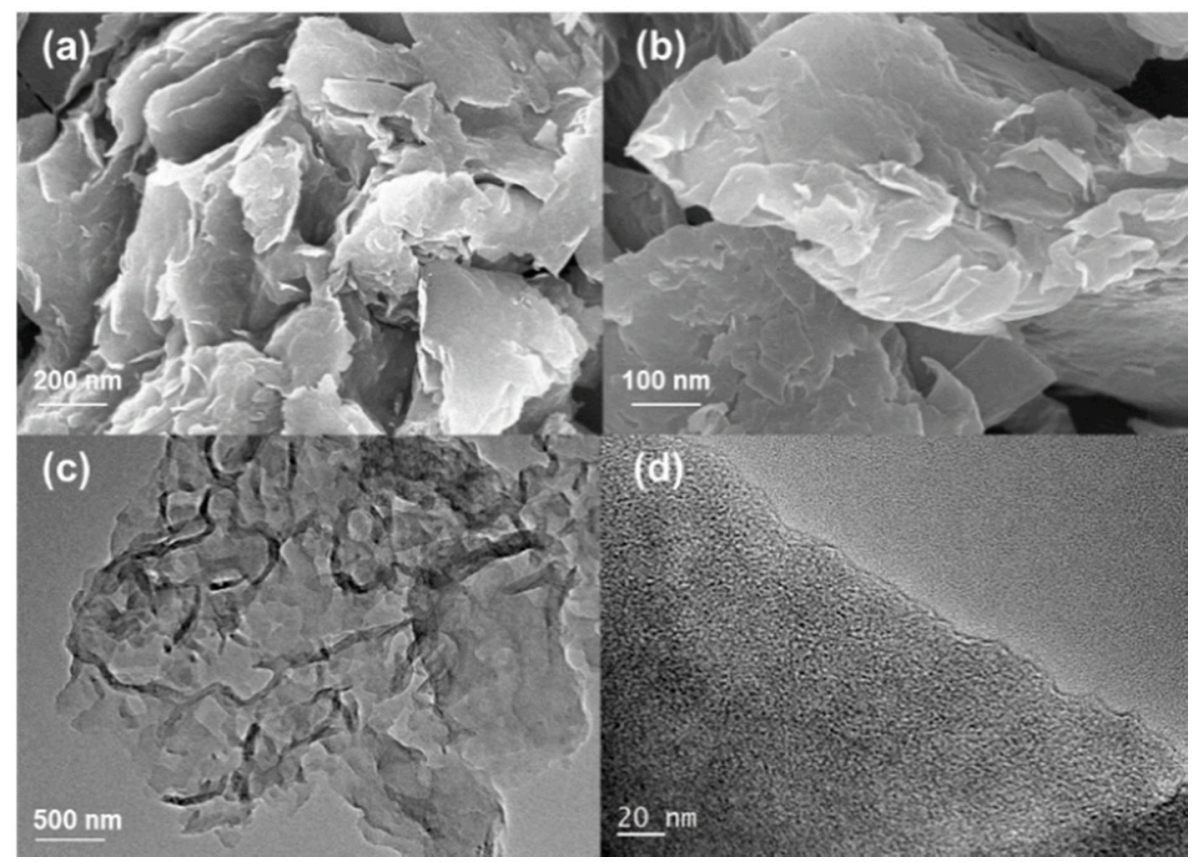

Figure 2. (a,b) SEM images of N-SAC; (c,d) TEM and HRTEM images of N-SAC.

\subsubsection{FT-IR and XPS Analysis}

Fourier transform infrared (FT-IR) spectra were carried out to investigate the chemical bonds in SAC and N-SAC. As is shown in Figure 3a, SAC and N-SAC showed the characteristic of C=O and C-O stretching vibrations at $1650 \mathrm{~cm}^{-1}$ and $1425 \mathrm{~cm}^{-1}$ respectively [29]. However, the new peak at $966 \mathrm{~cm}^{-1}$ in N-SAC verified the formation of N-H which demonstrated the successful doped of 
nitrogen in carbon framework. In the meantime, the peak at $1020-1360 \mathrm{~cm}^{-1}$ can be caused by the stretching vibration and bending vibration of nitrogen-containing functional groups such as $\mathrm{C}=\mathrm{N}$ and $\mathrm{C}-\mathrm{N}$ [30] and the strong and broad peak at $3412 \mathrm{~cm}^{-1}$ in N-SAC can be assigned to the asymmetric stretching vibration of $\mathrm{O}-\mathrm{H}$ bond of alcohols [5], phenols and a small number of amino groups adding with dicyandiamide.
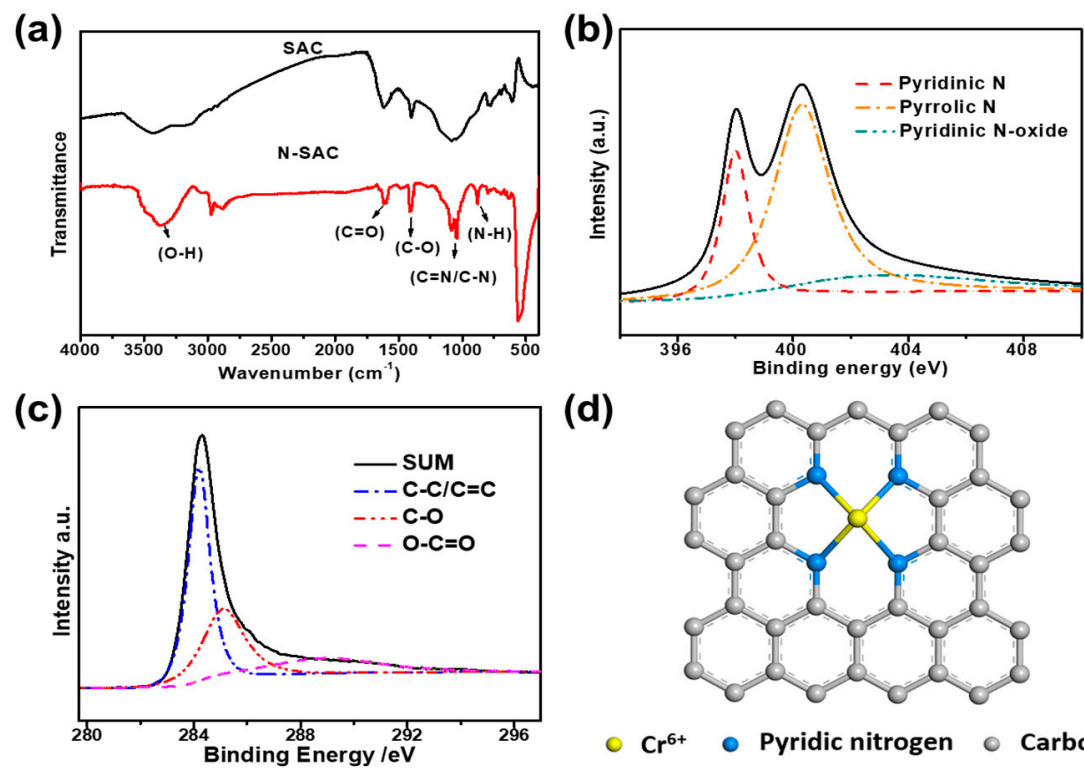

(d)

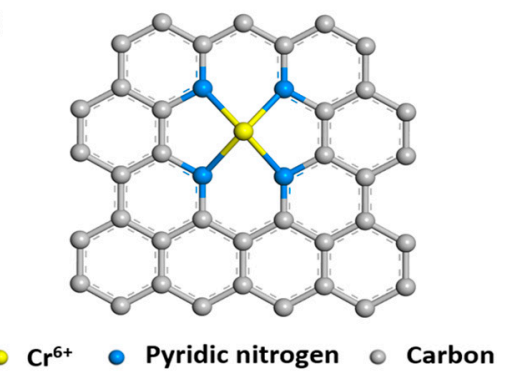

Figure 3. (a) Fourier transform infrared (FT-IR) spectra of N-SAC and SAC. (b,c) High resolution X-ray photoelectron spectroscopy (XPS) spectrum of N and C in N-SAC. (d) Possible hypothesis of chemical adsorption of $\mathrm{Cr}-\mathrm{N}_{4}$ structure in N-SAC.

Then, the X-ray photoelectron spectroscopy (XPS) were used to evaluate the composition and chemical bond in N-SAC carbon matrix. As shown in Figure 3b, the high-resolution N1s spectra demonstrated the successful doping of N into N-SAC and divided into three peaks, corresponding to pyridinic nitrogen $(398.2 \pm 0.3 \mathrm{eV})$, pyrrolic nitrogen $(400.2 \pm 0.3 \mathrm{eV})$ and pyridinic N-oxide $(402.9 \pm 0.2 \mathrm{eV})$ [17]. And in the C1s spectra, three major peaks with binding energy at $284.2( \pm 0.3 \mathrm{eV})$, $285.1( \pm 0.3 \mathrm{eV})$ and $288.7( \pm 0.3 \mathrm{eV})$ can be identified as $\mathrm{C}-\mathrm{C}(\mathrm{C}=\mathrm{C}), \mathrm{C}-\mathrm{O}$ and $\mathrm{O}-\mathrm{C}=\mathrm{O}$. The doping of $\mathrm{N}$ and $\mathrm{O}$ into N-SAC could effectively improve the electronic conductivity and stability and activate the sp2 carbon framework according to optimize the electron cloud density [27]. Furthermore, the doping of pyridinic-N could bond with $\mathrm{Cr}$ by coming into being the $\mathrm{Cr}-\mathrm{N}_{4}$ structure (Figure $3 \mathrm{~d}$ ), which could also enhance the accessibility of adsorption of $\mathrm{Cr}$ in waste water performance greatly.

The water contact angle measurement was implemented to investigate the impaction of $\mathrm{N}$-doping on wettability. As shown in Figure S3, the contact angle of $64.81^{\circ}$ indicates a great hydrophilicity of $\mathrm{N}-\mathrm{SAC}$, comparing with SAC $\left(85.29^{\circ}\right)$, because the introduction of $\mathrm{C}-\mathrm{N}$ bonds and $\mathrm{O}-\mathrm{H}$ bonds can significantly facilitate the fully wetting of the active species. Furthermore, the increase of hydrophilicity could make N-SAC easy to contact $\mathrm{Cr}(\mathrm{VI})$ ions in liquor and enhance the adsorption ability.

\subsection{Adsorption Studies of $\mathrm{Cr}(\mathrm{VI})$ on N-SAC}

In order to test the performance of sludge-based activated carbon for adsorption of $\mathrm{Cr}(\mathrm{VI})$ ions from aqueous solution, the activated carbon of SAC and N-SAC were used and investigate on different $\mathrm{pH}$.

\subsubsection{Effect of PH}

Figure 4a showed the adsorption capacity of SAC and N-SAC in terms of removal of $\mathrm{Cr}(\mathrm{VI})$ in different $\mathrm{pH}$, ranging from 2.0 to 8.0. As can be seen, the $\mathrm{pH}$ of aqueous solution has a strong impact 
on the adsorption process as it can influence the charge of functional groups on the adsorbent surface and the chemical forms of chromium.

(a)

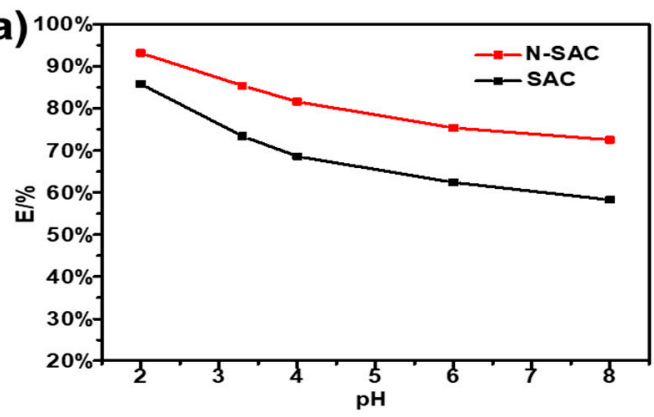

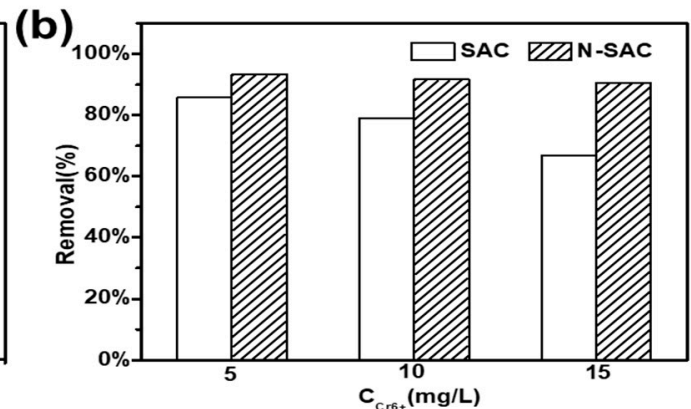

Figure 4. Kinetic model fitting at different concentrations: (a) $\mathrm{Cr}(\mathrm{VI})$ removal rates of SAC and N-SAC in different $\mathrm{pH}(2.0-8.0)$; (b) $\mathrm{Cr}(\mathrm{VI})$ removal rates of SAC and N-SAC in different concentration $(5,10$, $\left.15 \mathrm{mg} \mathrm{L}^{-1}\right)$.

In different $\mathrm{pH}$ value solutions, $\mathrm{Cr}(\mathrm{VI})$ can existed as chromic acid $\left(\mathrm{H}_{2} \mathrm{CrO}_{4}\right)$, hydrogen chromate ion $\left(\mathrm{HCrO}^{4-}\right)$ and chromate ion $\left(\mathrm{CrO}_{4}{ }^{2-}\right)$ [31]. Under acidic conditions, the surface functional groups of the activated carbon combined with $\mathrm{H}^{+}$in the solution to become protonated and positively charged, resulting that $\mathrm{Cr}(\mathrm{VI})$ reduced into $\mathrm{Cr}(\mathrm{III})$ via this reaction (Equations (4) and (5)). As shown in Figure $4 \mathrm{a}$, the maximum removal rate $(85.8 \%)$, can be attained at $\mathrm{pH}=2$ in SAC, while it fell to $58.2 \%$ at $\mathrm{pH}=8.0$. With the amount of $\mathrm{OH}^{-}$increased, the decreased removal rate of $\mathrm{Cr}(\mathrm{VI})$ was the result of the surface electrostatic repulsion. The as-prepared N-SAC showed similar curve pattern, it could remove almost $93.2 \%$ of $\mathrm{Cr}(\mathrm{VI})$ in waste water on lower $\mathrm{pH}$, which was much higher than that of SAC, because the nanosheets structure and mesopores could increase the contact area between adsorbent and $\mathrm{Cr}$-contained solution and enhance the adsorbing capacity. Besides, the N-SAC suffered little impact from alkaline condition, $\mathrm{Cr}(\mathrm{VI})$ removal rate has decreased by $20.8 \%$ as the $\mathrm{pH}$ value varied from 2.0 to 8.0 in the solution, which was less than the decrease for SAC $(25.6 \%)$ in the same process. It can be ascribed to the doping of $\mathrm{N}$ activated the sp2 carbon, which exposed more active sites for adsorption and improved the stability of carbon matrix in strong alkaline condition. Meanwhile, amino groups $\left(-\mathrm{NH}_{2}\right)$ in N-SAC also played an important role in anion adsorption in high $\mathrm{pH}$ [32]. All these results indicated that $\mathrm{N}$-doped modification on SAC was effective in the adsorption process of $\mathrm{Cr}(\mathrm{VI})$ by N-SAC.

\subsubsection{Comparison of Adsorption Performance}

The operating condition also affected the adsorption capacity of adsorbents. Figure $4 \mathrm{~b}$ showed the performance of SAC and N-SAC on the removal rate of $\mathrm{Cr}(\mathrm{VI})$ from different concentration aqueous at $\mathrm{pH}=2.0$. When the solution concentration of $\mathrm{Cr}(\mathrm{VI})$ increased from $5 \mathrm{mg} \cdot \mathrm{L}^{-1}$ to $15 \mathrm{mg} \cdot \mathrm{L}^{-1}$, the removal rate of $\mathrm{Cr}(\mathrm{VI})$ on $\mathrm{SAC}$ has a drop from $85.8 \%$ to $66.7 \%$. However, N-SAC showed $93.2 \%$ of removal rate at $5 \mathrm{mg} \cdot \mathrm{L}^{-1}$ and its removal efficiency was only decreased by $5.9 \%$ as the concentration of $\mathrm{Cr}(\mathrm{VI})$ was doubled, indicating the higher adsorption capacity of N-SAC than SAC at high concentrations of $\mathrm{Cr}(\mathrm{VI})$. It elucidated that the nitrogen modification brought N-SAC with stable and high adsorption capacity in different conditions, which can be overcame the limitation of using condition in traditional activated carbon.

\subsubsection{Adsorption Kinetics}

In order to investigate the adsorption dynamics of $\mathrm{Cr}(\mathrm{VI})$ on N-SAC, the kinetic models of pseudo-first order and pseudo-second order were fitted to experimental data and the linear fits are shown in Figure 5a,b [33,34]. According to the results (see Table 2), the calculated correlation coefficient value of pseudo-second-order $\left(R^{2}=0.9984\right)$ is much higher than that of pseudo-first-order model $\left(R^{2}\right.$ 
$=0.9184)$, indicating that the pseudo-second-order model was suitable to describe the adsorption kinetic of $\mathrm{Cr}(\mathrm{VI})$. As the concentration of $\mathrm{Cr}(\mathrm{VI})$ increased, the rate constant $(\mathrm{k})$ of $\mathrm{C}_{\mathrm{Cr}(\mathrm{VI})}=\mathrm{mg} \cdot \mathrm{L}^{-1}$ is higher than that of $15 \mathrm{mg} \cdot \mathrm{L}^{-1}$ [31], indicating the decreased adsorption rate of $\mathrm{Cr}(\mathrm{VI})$ as the its initial concentration increased. The values of $\mathrm{k} 2$ were decreased from 0.0264 to $0.0186 \mathrm{mg} . \mathrm{min}^{-1}$ as the initial $\mathrm{Cr}$ (VI) was from $10 \mathrm{mg} \cdot \mathrm{L}^{-1}$ to $15 \mathrm{mg} \cdot \mathrm{L}^{-1}$, which was attributed to the lower competition for the adsorption surface sites at lower concentration and the active sites on the surface can adsorb $\mathrm{Cr}(\mathrm{VI})$ ions faster, so the pseudo-second-order kinetic rate constant is higher at lower $\mathrm{Cr}$ (VI) concentration. The result further confirms that N-SAC possesses a high adsorption rate for $\mathrm{Cr}(\mathrm{VI})$, which is mainly attributed to its unique hierarchical porous structure combined with a high specific surface area.
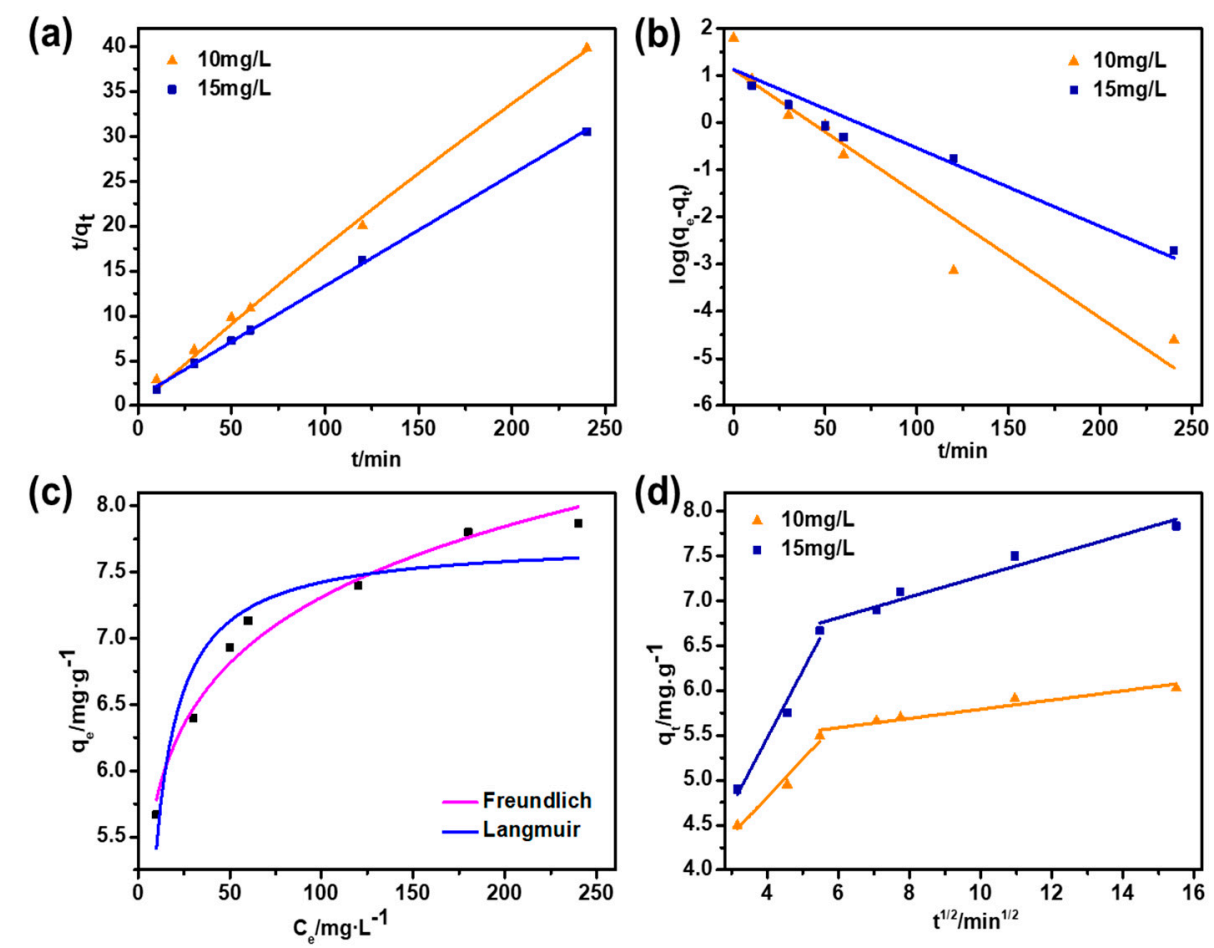

Figure 5. (a) Pseudo-first-order kinetic adsorption model fitting; (b) Pseudo-second-order kinetic adsorption model fitting; (c) Adsorption isotherm; (d) IPD fitting with N-SAC.

Table 2. Kinetic parameters of $\mathrm{Cr}(\mathrm{VI})$ adsorbed by N-SAC at different initial concentration.

\begin{tabular}{|c|c|c|c|c|c|c|c|}
\hline \multirow{2}{*}{$\begin{array}{c}\mathrm{C}_{0} \\
\left(\mathrm{mg} \cdot \mathrm{L}^{-1}\right)\end{array}$} & \multirow{2}{*}{$\underset{\left(\mathrm{mg} \cdot \mathrm{g}^{-1}\right)}{\left.\mathrm{q}_{\mathrm{e}}\right)}$} & \multicolumn{3}{|c|}{ Pseudo-First Order } & \multicolumn{3}{|c|}{ Pseudo-Second Order } \\
\hline & & $\begin{array}{c}\mathrm{q}_{\mathrm{e}, \mathrm{cal1}} \\
\left(\mathrm{mg} \cdot \mathrm{g}^{-1}\right)\end{array}$ & $\begin{array}{c}\mathrm{k}_{1} \\
\left(\min ^{-1}\right)\end{array}$ & $\mathbf{R}^{2}$ & $\begin{array}{c}\mathrm{q}_{\mathrm{e}, \mathrm{cal1}} \\
\left(\mathrm{mg} \cdot \mathrm{g}^{-1}\right)\end{array}$ & $\begin{array}{c}\mathrm{k}_{2} \\
\left(\mathrm{mg} \cdot \mathrm{min}^{-1}\right)\end{array}$ & $\mathbf{R}^{2}$ \\
\hline 10 & 6.03 & 3.068 & 0.0263 & 0.9184 & 6.271 & 0.0264 & 0.9984 \\
\hline 15 & 7.84 & 3.092 & 0.0167 & 0.08775 & 7.831 & 0.0186 & 0.9993 \\
\hline
\end{tabular}

\subsubsection{Adsorption Isotherm}

The adsorption isotherm, which is an important parameter for investigating the distribution of adsorbent on the surface of the adsorbent material and estimating its adsorption capacity. Thus, Langmuir and Freundlich models were fitted to experimental data and the results are shown in Figure 5c [35].

Table 3 shows the isothermal parameters of Freundlich and Langmuir models. According to results, the Freundlich model was fitted well to experimental data. The Freundlich model assumes that adsorption occurs over a heterogeneous surface in multilayer, assuming that adsorbent surface sites have a spectrum of different binding energies [30]. 
Table 3. Isothermal parameters of Cr(VI) adsorbed by N-SAC.

\begin{tabular}{cc}
\hline Langmuir & Freundlich \\
\hline $\mathrm{Q}_{\mathrm{m}}=7.74\left(\mathrm{mg} \cdot \mathrm{g}^{-1}\right)$ & $\mathrm{k}_{\mathrm{F}}=4.57$ \\
$\mathrm{k}_{\mathrm{a}}=0.23\left(\mathrm{~L} \cdot \mathrm{mg}^{-1}\right)$ & $\mathrm{n}_{\mathrm{F}}=9.81$ \\
$\mathrm{R}^{2}=0.8773$ & $\mathrm{R}^{2}=0.9710$ \\
\hline
\end{tabular}

\subsubsection{Intraparticle Diffusion Model (IPD)}

The IPD fitting curve was shown in Figure $5 d$ and the relevant parameters are summarized in Table 4. It can be seen that the fitting curve can be divided into two sections at different initial concentrations [34], which represented the adsorption process of N-SAC on $\mathrm{Cr}(\mathrm{VI})$ was dual-stage. The first stage (Step I) was the macroporous diffusion adsorption of N-SAC, $\mathrm{Cr}(\mathrm{VI})$ ions diffused from solution to the adsorption sites on the surface of N-SAC macroporous surface. In step II, Cr(VI) ions diffused into the internal microporous channels of N-SAC and adsorbed on the surface of micropores. Among these two stage, the diffusion rate $\left(\mathrm{K}_{\mathrm{id} 2}\right)$ of micropores was obviously slower than that of macrospores $\left(\mathrm{K}_{\mathrm{id} 1}\right)$, indicating that the diffusion in micropores should be the rate-controlling step [36]. With the increase of initial concentration of $\mathrm{Cr}(\mathrm{VI})$ from 10 to $15 \mathrm{mg} \cdot \mathrm{L}^{-1}$, the diffusion rates were increasing, which elucidated the diffusion driving force of $\mathrm{Cr}(\mathrm{VI})$ accelerated the adsorption process.

Table 4. The IPD model parameters of $\mathrm{Cr}(\mathrm{VI})$ adsorption.

\begin{tabular}{cccccc}
\hline \multirow{2}{*}{$\mathbf{C}_{\mathbf{0}, \mathbf{~} \mathbf{~ g} \cdot \mathbf{L}^{-\mathbf{1}}}$} & $\mathbf{C}, \mathbf{~} \mathbf{~ g} \cdot \mathbf{g}^{-\mathbf{1}}$ & \multicolumn{2}{c}{ Step I } & \multicolumn{2}{c}{ Step II } \\
\cline { 3 - 6 } & & $\mathbf{K}_{\mathbf{i d} \mathbf{1}}$ & $\mathbf{R}^{\mathbf{2}}$ & $\mathbf{K}_{\mathbf{i d} \mathbf{2}}$ & $\mathbf{R}^{\mathbf{2}}$ \\
\hline 10 & 0.42 & 2.69 & 0.94 & 0.62 & 0.92 \\
15 & 0.59 & 3.23 & 0.99 & 0.73 & 0.94 \\
\hline
\end{tabular}

\subsubsection{Adsorption Thermodynamics}

The thermodynamic parameters (Table 5) showed that $\Delta \mathrm{H}^{0}$ was $79.46 \mathrm{~kJ} \cdot \mathrm{mol}^{-1}$, indicating that the adsorption process was endothermic. While $\Delta S^{0}$ was positive number that illustrated the disorder degree of the adsorbent surface increased during the adsorption process. Chemisorption and physical adsorption can be judged by $\Delta G^{0}$ [37]. When the adsorption was physical adsorption, $-20<\Delta G^{0}$ $<0 \mathrm{~kJ} \cdot \mathrm{mol}^{-1}$, otherwise, $-400<\Delta \mathrm{G}^{0}<-80 \mathrm{~kJ} \cdot \mathrm{mol}^{-1}$ [38]. In this experiment, $\Delta \mathrm{G}^{0}$ is in -9.75 to $-22.14 \mathrm{~kJ} \cdot \mathrm{mol}^{-1}$, indicating that the adsorption process of $\mathrm{Cr}(\mathrm{VI})$ on N-SAC was mainly physical adsorption-a reversible process, under certain temperature and pressure conditions adsorption would reach equilibrium.

Table 5. The thermodynamic parameters of $\mathrm{Cr}(\mathrm{VI})$ adsorption.

\begin{tabular}{|c|c|c|c|c|c|c|}
\hline \multicolumn{5}{|c|}{$\Delta \mathrm{G}^{0} / \mathrm{kJ} \cdot \mathrm{mol}^{-1}$} & \multirow{2}{*}{$\begin{array}{c}\Delta \mathrm{H}^{0} \\
\left(\mathrm{~kJ} \cdot \mathrm{mol}^{-1}\right)\end{array}$} & \multirow{2}{*}{$\begin{array}{c}\Delta \mathrm{S}^{0} \\
\left(\mathrm{~kJ} \cdot \mathrm{mol}^{-1} \cdot \mathrm{K}^{-1}\right)\end{array}$} \\
\hline $288 K$ & $298 K$ & $308 K$ & $318 K$ & $328 \mathrm{~K}$ & & \\
\hline-9.75 & -12.85 & -15.95 & -19.05 & -22.14 & 79.46 & 0.3098 \\
\hline
\end{tabular}

\subsection{Cr (VI) Adsorption Mechanism}

XPS was conducted to measure the elemental species to confirm the adsorption process of $\mathrm{Cr}(\mathrm{VI})$ on SAC and N-SAC. In the $\mathrm{Cr}(\mathrm{VI})$ solution, $\mathrm{Cr}(\mathrm{VI})$ can be expressed by a series of negative ions whose form conversions were correlated with the $\mathrm{pH}$ value, including $\mathrm{HCr}_{2} \mathrm{O}_{7}^{-}, \mathrm{HCrO}_{4}^{-}, \mathrm{Cr}_{2} \mathrm{O}_{7}{ }^{2-}$ and $\mathrm{CrO}_{4}{ }^{2-}$. Normally, $\mathrm{HCrO}_{4}{ }^{-}$group was the predominant form in solution with $\mathrm{pH}<6.5$ [39]. As shown in Figure S4a, there were obviously N-SAC corresponding to C 1s, O 1s, N 1s, while the additional Cr $2 p$ peak was found out after adsorption. The spectra of the $\mathrm{Cr} 2 \mathrm{p}$ showed two major peaks of $\mathrm{Cr} 2 \mathrm{p}$ on $\mathrm{N}-\mathrm{SAC}$, which were corresponded to $\mathrm{Cr} 2 \mathrm{p}_{3 / 2}$ and $\mathrm{Cr} 2 \mathrm{p}_{1 / 2}$, respectively [40]. After peak differential 
analysis, the $\mathrm{Cr} 2 \mathrm{p}$ spectrum can be divided into three peaks (Figure S4c), corresponding to $\mathrm{Cr}$ (III) located at $576.3 \mathrm{eV}\left(\mathrm{Cr} 2 \mathrm{p}_{3 / 2}\right)$ and $586.9 \mathrm{eV}\left(\mathrm{Cr} 2 \mathrm{p}_{1 / 2}\right)$ and $\mathrm{Cr}(\mathrm{VI})$ located at $577.8 \mathrm{eV}\left(\mathrm{Cr} 2 \mathrm{p}_{3 / 2}\right)$ [41]. It indicated that a part of $\mathrm{Cr}(\mathrm{VI})$ is reduced to the low toxic $\mathrm{Cr}(\mathrm{III})$ during the adsorption on N-SAC and the residual of $\mathrm{Cr}(\mathrm{VI})$ is removed by physical adsorption. It indicated that $\mathrm{Cr}(\mathrm{VI})$ adsorption including two process: a part of $\mathrm{Cr}(\mathrm{VI})$ is reduced to the low toxic $\mathrm{Cr}(\mathrm{III})$ as Equations (7) and (8) [42] and the residual of $\mathrm{Cr}(\mathrm{VI})$ is removed by physical adsorption.

$$
\begin{gathered}
\mathrm{HCrO}_{4}^{-}+7 \mathrm{H}^{+}+3 \mathrm{e}^{-} \rightarrow \mathrm{Cr}^{3+}+4 \mathrm{H}_{2} \mathrm{O} \\
\mathrm{Cr}_{2} \mathrm{O}_{7}^{2-}+14 \mathrm{H}^{+}+6 \mathrm{e}^{-} \rightarrow 2 \mathrm{Cr}^{3+}+7 \mathrm{H}_{2} \mathrm{O}
\end{gathered}
$$

where the most of electron donors $\left(\mathrm{e}^{-}\right)$are from amino groups in N-SAC.

Besides, the $\mathrm{N}$ 1s peak has decreased after adsorption (Figure S4a), illustrating that nitrogen species of N-SAC were related to the $\mathrm{Cr}(\mathrm{VI})$ reduction. This result showed that the adsorption mechanism of $\mathrm{Cr}(\mathrm{VI})$ were multi step, including chemical reduction and physical adsorption. In comparison, XPS spectrum of $\mathrm{Cr}(\mathrm{VI})$ adsorption on SAC only showed peaks corresponding to $\mathrm{C} 1 \mathrm{~s}, \mathrm{O} 1 \mathrm{~s}$ and a little amount of $\mathrm{Cr} 2 \mathrm{p}$ (Figure $\mathrm{S} 4 \mathrm{~b}$ ). The $\mathrm{Cr} 2 \mathrm{p}$ peak on SAC was just resolved into two peak of $\mathrm{Cr}(\mathrm{VI})$, at $577.8 \mathrm{eV}\left(\mathrm{Cr} 2 \mathrm{p}_{3 / 2}\right)$ and $587.1 \mathrm{eV}\left(\mathrm{Cr} 2 \mathrm{p}_{1 / 2}\right)$ [43], elucidating the $\mathrm{Cr}(\mathrm{VI})$ on SAC was merely physical adsorption (Figure $\mathrm{S} 4 \mathrm{~d}$ ).

In all, reduction occurred along with the adsorption processes and the reducing agent was nitrogen atom groups on N-SAC. After reduction, the generating $\mathrm{Cr}$ (III) species were immobilized onto the adsorbent and residual $\mathrm{Cr}(\mathrm{VI})$ ions were adsorbed on the surface and pore of N-SAC, which has a higher removal rate of $\mathrm{Cr}(\mathrm{VI})$ than that of SAC. This results can also be proved in DFT calculation.

\subsection{DFT Calculation}

To further understanding the primary effect of doping of $\mathrm{N}$ in carbon matrix, first-principles calculation was carried out to investigate the structure of simplified pure graphene model (Gra) and N-doped graphene model based on DFT methods and XPS results. Previous works demonstrated that atom with decreased charge density could serve as active sites for adsorbing. As shown in Figure 6, Gra-N model show lower Mulliken charge with -0.816 , which value is much negative than pure Gra model (-0.381). These dates indicated that the doping of $\mathrm{N}$ could significantly decrease the Mulliken charge of adsorbent due to its high electronegativity, which may help materials to enhance its adsorption ability. Besides, the electronic cloud distribution at the highest occupied molecular orbital (HOMO) were also calculated on Figures S5 and S6. According to the frontier molecular orbital theory, the narrower of the gap between the HOMO of adsorbent the lowest unoccupied molecular orbital (LUMO) of adsorbent, the easier for the charge transfer process and the lower the adsorption energy. As shown in Figure 6 and Table 6, Gra-N presented higher HOMO energy and more negative adsorption energy than pure Gra, demonstrating the doping of $\mathrm{N}$ make it easier to capture $\mathrm{HCrO}^{-}$ into carbon matrix during adsorption process.

(a)

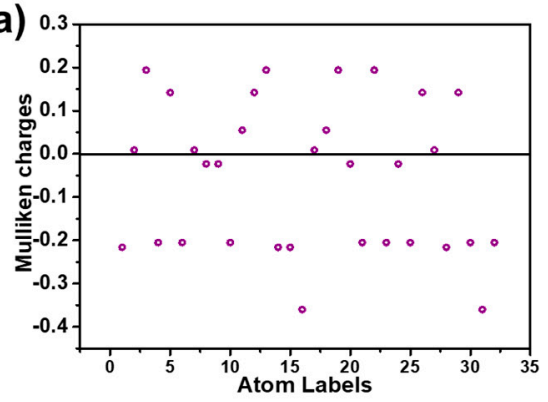

(b)

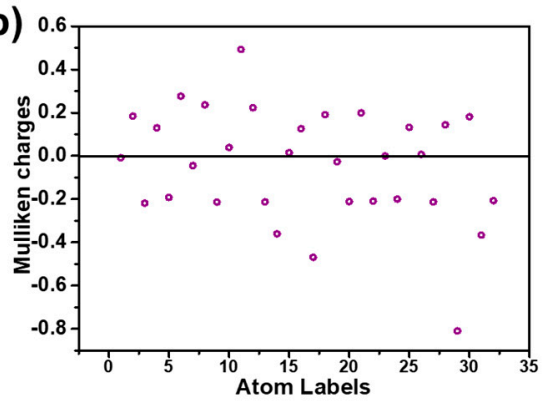

Figure 6. Mulliken charge distribution of Gra (a) and Gra-N (b) respectively. 
Table 6. HOMO Energy Level and adsorption energy on Different Models.

\begin{tabular}{ccc}
\hline Adsorbents & HOMO Energy (eV) & Adsorption Energy (eV) \\
\hline Gra & -5.57492 & -0.1865 \\
Gra-N & -3.39052 & -0.5782 \\
\hline
\end{tabular}

\subsection{Regeneration Investigation}

The study of thermal regeneration of the adsorbed carbon nanosheets (N-SAC) was carried out in one cycle(N-SAC') and adsorption effect was shown in Figure S7. As it can be seen, the removal rate of $\mathrm{Cr}(\mathrm{VI})$ by N-SAC' still showed high adsorption capacity, at $90.8 \%, 88.6 \%$ and $86.19 \%$ in $\mathrm{C}_{\mathrm{Cr}(\mathrm{VI})}$ $=5 \mathrm{mg} \cdot \mathrm{L}^{-1}, 10 \mathrm{mg} \cdot \mathrm{L}^{-1}$ and $15 \mathrm{mg} \cdot \mathrm{L}^{-1}$ respectively, which even higher than SAC in three different concentrations. It suggested that $\mathrm{N}^{-S A C} \mathrm{C}^{\prime}$ has high specific surface and enough active site after regeneration. As it shown in the Figure S8a, the phase impurity of N-SAC, including the crystalline $\mathrm{Cr}_{2} \mathrm{O}_{3}$ and $\mathrm{C}$, which could be indexed based on crystalline $\mathrm{Cr}_{2} \mathrm{O}_{3}$ (JCPDS No. 85-0869, No. 06-0504) and Carbon (JCPDS No. 75-0444). After regeneration, Figure S8a showed that N-SAC' sample only has a peak of $\mathrm{C}$, suggesting that partial reduced $\mathrm{Cr}$ (III) in N-SAC was converted to metallic oxide $\mathrm{Cr}_{2} \mathrm{O}_{3}$ (Equations (9) and (10)) by carbon on high temperature and can be wiped out easily via caustic washing [44], which can be proved by XPS of N-SAC'(Figure S9).

$$
\begin{gathered}
3^{-} \mathrm{OH}+\mathrm{Cr}^{3+} \rightarrow\left({ }^{-} \mathrm{OH}\right)_{3} \mathrm{Cr}^{3+} \\
2 \mathrm{Cr}(\mathrm{OH})_{3} \rightarrow \mathrm{Cr}_{2} \mathrm{O}_{3}+3 \mathrm{H}_{2} \mathrm{O}
\end{gathered}
$$

The high adsorption efficiency of N-SAC' can be attributed to the reaction of $\mathrm{Cr}(\mathrm{VI})$ and $\mathrm{Cr}(\mathrm{III})$ adsorbed on the N-SAC during the thermal regeneration. N-SAC' can elute $\mathrm{Cr}_{2} \mathrm{O}_{3}$ easily and reuse on adsorption of $\mathrm{Cr}(\mathrm{VI})$ ion waste water [45-47].

\section{Conclusions}

In summary, a low-cost and convenient strategy has been developed to produce activated carbon nanosheets by using sewage sludge. Under the synergetic effect of $\mathrm{KOH}$ and dicyandiamide during the activation process, N-SAC showed good performance, such as high surface area, porous structure and high adsorption capacity of metal ions $(\mathrm{Cr}(\mathrm{VI})$. As a resultant, the adsorbent $\mathrm{N}-\mathrm{SAC}$ showed its good adsorption property of $\mathrm{Cr}(\mathrm{VI})$ in waste water at $93.2 \%$ removal rate. Additionally, the recycled adsorbent still remained a high removal rate at $90.8 \%$ of $\mathrm{Cr}(\mathrm{VI})$ in solution after regeneration process. This facile route developed here may offer possibilities for mass production of biomass-derived carbon materials for waste water treatment and greatly promising for industrialization.

Supplementary Materials: The following are available online at http:/ /www.mdpi.com/2079-4991/9/2/265/s1. Figure S1: (a) and (b) The SEM images of raw materials of sewage sludge carbon (SS); Figure S2: (a) and (b) The SEM image of sludge-based activated carbon (SAC); Figure S3: Water contact angle measurement for (a) N-SAC and (b) SAC; Figure S4: (a), (b) X-ray photoelectron spectroscopy (XPS) of N-SAC and SAC before and after Cr6+ adsorption, (c), (d) High resolution XPS of Cr6+ after adsorption in N-SAC and SAC; Figure S5: (a) Atom label and (b) Mulliken charge density and (c) HOMO energy of carbon atoms in Gra model. Atom color code: yellow is carbon and blue is hydrogen; Figure S6: (a) Atom label and (b) Mulliken charge density and (c) HOMO energy of carbon atoms in Gra-N model. Atom color code: yellow is carbon and blue is hydrogen; Figure S7: The adsorption effect of Cr6+ removing from wastewater by SAC, N-SAC and N-SAC', (a) removal rate, (b) color change of solution before and after adsorption; Figure S8: (a) XRD pattern of N-SAC after calcination, (b) XRD pattern of N-SAC' after regeneration; Figure S9: X-ray photoelectron spectroscopy (XPS) of (a) N-SAC', and high resolution XPS of (b) (c) (d) N, C and Cr respectively.

Author Contributions: Y.W. performed experiments and drafted the manuscript; W.Z. (Weinan Zhao) calculated experimental data and drafted the manuscript, too. Notably, Y.W. and W.Z. (Weinan Zhao) contributed equally to this work and should be considered co-first authors. W.Z. (Wanlan Zheng) analysed the experimental data and form. S.C. provided the idea for the manuscript and J.Z. edited the manuscript.

Funding: The work was financially supported by the National Natural Science Foundation of China (51473074 and 21601079) and the Doctor Start-up Fund of Shandong University of Technology (4041/416024). 
Conflicts of Interest: The authors declare no conflict of interest.

\section{References}

1. Smith, K.; Fowler, G.; Pullket, S.; Graham, N. Sewage sludge-based adsorbents: A review of their production, properties and use in water treatment applications. Water Res. 2009, 43, 2569-2594. [CrossRef] [PubMed]

2. Caicedo, C.; Rosenwinkel, K.-H.; Exner, M.; Verstraete, W.; Suchenwirth, R.; Hartemann, P.; Nogueira, R. Legionella occurrence in municipal and industrial wastewater treatment plants and risks of reclaimed wastewater reuse: Review. Water Res. 2019, 149, 21-34. [CrossRef] [PubMed]

3. Tong, X.-J.; Li, J.-Y.; Yuan, J.-H.; Xu, R.-K. Adsorption of $\mathrm{Cu}(\mathrm{II})$ by biochars generated from three crop straws. Chem. Eng. J. 2011, 172, 828-834. [CrossRef]

4. Lu, H.; Zhang, W.; Yang, Y.; Huang, X.; Wang, S.; Qiu, R. Relative distribution of $\mathrm{Pb}^{2+}$ sorption mechanisms by sludge-derived biochar. Water Res. 2012, 46, 854-862. [CrossRef]

5. Liu, S.; Chen, X.; Liu, Z.; Wang, H. Activated carbon with excellent chromium(VI) adsorption performance prepared by acid-base surface modification. J. Hazardous Mat. 2007, 141, 315-319. [CrossRef]

6. Liu, Q.; Liu, Q.; Liu, B.; Hu, T.; Liu, W.; Yao, J. Green synthesis of tannin-hexamethylendiamine based adsorbents for efficient removal of Cr(VI). J. Hazardous Mat. 2018, 352, 27-35. [CrossRef]

7. Li, Y.; Zhu, S.; Liu, Q.; Chen, Z.; Gu, J.; Zhu, C.; Lu, T.; Zhang, D.; Ma, J. N-doped porous carbon with magnetic particles formed in situ for enhanced Cr(VI) removal. Water Res. 2013, 47, 4188-4197. [CrossRef]

8. Li, D.; Chen, L.; Zhao, J.; Zhang, X.; Wang, Q.; Wang, H.; Ye, N. Evaluation of the pyrolytic and kinetic characteristics of Enteromorpha prolifera as a source of renewable bio-fuel from the Yellow Sea of China. Chem. Eng. Res. Design 2010, 88, 647-652. [CrossRef]

9. Jeyaseelan, S.; Lu, G. Development of adsorbent/catalyst from municipal wastewater sludge. Water Sci. Tech. 1996, 34, 499-505. [CrossRef]

10. Li, W.-H.; Yue, Q.-Y.; Gao, B.-Y.; Wang, X.-J.; Qi, Y.-F.; Zhao, Y.-Q.; Li, Y.-J. Preparation of sludge-based activated carbon made from paper mill sewage sludge by steam activation for dye wastewater treatment. Desalination 2011, 278, 179-185. [CrossRef]

11. Wang, H.; Xu, Z.; Kohandehghan, A.; Li, Z.; Cui, K.; Tan, X.; Stephenson, T.J.; King'Ondu, C.K.; Holt, C.M.B.; Olsen, B.C.; et al. Interconnected carbon nanosheets derived from hemp for ultrafast supercapacitors with high energy. ACS Nano 2013, 7, 5131-5141. [CrossRef] [PubMed]

12. Du, W.; Wang, X.; Sun, X.; Zhan, J.; Zhang, H.; Zhao, X. Nitrogen-doped hierarchical porous carbon using biomass-derived activated carbon/carbonized polyaniline composites for supercapacitor electrodes. J. Electrol. Chem. 2018, 827, 213-220. [CrossRef]

13. Ye, X.-N.; Lu, Q.; Wang, X.; Guo, H.-Q.; Cui, M.-S.; Dong, C.-Q.; Yang, Y.-P. Catalytic Fast Pyrolysis of Cellulose and Biomass to Selectively Produce Levoglucosenone Using Activated Carbon Catalyst. ACS Sustainable Chem. Eng. 2017, 5, 10815-10825. [CrossRef]

14. Li, X.; Li, H.; Liu, T.; Hei, Y.; Hassan, M.; Zhang, S.; Lin, J.; Wang, T.; Bo, X.; Wang, H.-L.; et al. The biomass of ground cherry husks derived carbon nanoplates for electroChem. sensing. Sensors Actuators B Chem. 2018, 255, 3248-3256. [CrossRef]

15. Weng, C.-H.; Lin, Y.-T.; Tzeng, T.-W. Removal of methylene blue from aqueous solution by adsorption onto pineapple leaf powder. J. Hazardous Mat. 2009, 170, 417-424. [CrossRef] [PubMed]

16. Luo, T.; Tian, X.; Yang, C.; Luo, W.; Nie, Y.; Wang, Y. Polyethylenimine-Functionalized Corn Bract, an Agricultural Waste Material, for Efficient Removal and Recovery of Cr(VI) from Aqueous Solution. J. Agric. Food Chem. 2017, 65, 7153-7158. [CrossRef] [PubMed]

17. Luo, H.; Jiang, W.-J.; Zhang, Y.; Niu, S.; Tang, T.; Huang, L.-B.; Chen, Y.-Y.; Wei, Z.-D.; Hu, J.-S. Self-terminated activation for high-yield production of N,P-codoped nanoporous carbon as an efficient metal-free electrocatalyst for Zn-air battery. Carbon 2018, 128, 97-105. [CrossRef]

18. Bedia, J.; Monsalvo, V.; Rodriguez, J.; Mohedano, A.; Garcia-Matamoros, J.B. Iron catalysts by Chem. activation of sewage sludge with FeCl 3 for CWPO. Chem. Eng. J. 2017, 318, 224-230. [CrossRef]

19. Sud, D.; Mahajan, G.; Kaur, M. Agricultural waste material as potential adsorbent for sequestering heavy metal ions from aqueous solutions - A review. Bioresource Tech. 2008, 99, 6017-6027. [CrossRef] 
20. Pezoti, O.; Cazetta, A.L.; Bedin, K.C.; Souza, L.S.; Martins, A.C.; Silva, T.L.; Júnior, O.O.S.; Visentainer, J.V.; Almeida, V.C. NaOH-activated carbon of high surface area produced from guava seeds as a high-efficiency adsorbent for amoxicillin removal: Kinetic, isotherm and thermodynamic studies. Chem. Eng. J. 2016, 288, 778-788. [CrossRef]

21. Jiang, T.-Y.; Jiang, J.; Xu, R.-K.; Li, Z. Adsorption of $\mathrm{Pb}(\mathrm{II})$ on variable charge soils amended with rice-straw derived biochar. Chemosphere 2012, 89, 249-256. [CrossRef] [PubMed]

22. Sun, D.; Guo, S.; Ma, N.; Wang, G.; Ma, C.; Hao, J.; Xue, M.; Zhang, X. Sewage sludge pretreatment by microwave irradiation combined with activated carbon fibre at alkaline $\mathrm{pH}$ for anaerobic digestion. Water Sci. Tech. 2016, 73, 2882-2887. [CrossRef] [PubMed]

23. Silva, T.L.; Ronix, A.; Pezoti, O.; Souza, L.S.; Leandro, P.K.; Bedin, K.C.; Beltrame, K.K.; Cazetta, A.L.; Almeida, V.C. Mesoporous activated carbon from industrial laundry sewage sludge: Adsorption studies of reactive dye Remazol Brilliant Blue R. Chem. Eng. J. 2016, 303, 467-476. [CrossRef]

24. Jiang, J.; Xu, R.-K. Application of crop straw derived biochars to $\mathrm{Cu}(\mathrm{II})$ contaminated Ultisol: Evaluating role of alkali and organic functional groups in $\mathrm{Cu}(\mathrm{II})$ immobilization. Bioresource Tech. 2013, 133, 537-545. [CrossRef] [PubMed]

25. Lin, Q.; Cheng, H.; Chen, G. Preparation and characterization of carbonaceous adsorbents from sewage sludge using a pilot-scale microwave heating equipment. J. Anal. Appl. Pyrolysis 2012, 93, 113-119. [CrossRef]

26. Wen, X.; Liu, H.; Zhang, L.; Zhang, J.; Fu, C.; Shi, X.; Chen, X.; Mijowska, E.; Chen, M.-J.; Wang, D.-Y.; et al. Large-scale converting waste coffee grounds into functional carbon materials as high-efficient adsorbent for organic dyes. Bioresource Tech. 2019, 272, 92-98. [CrossRef] [PubMed]

27. Wang, D.; Zhang, G.; Dai, Z.; Zhou, L.; Bian, P.; Zheng, K.; Wu, Z.; Cai, D. Sandwich-like Nanosystem for Simultaneous Removal of Cr(VI) and Cd(II) from Water and Soil. ACS Appl. Mater. Interfaces 2018, 10, 18316-18326. [CrossRef] [PubMed]

28. Jia, S.; Wang, Y.; Tian, P.; Zhou, S.; Cai, H.; Gao, H.; Zang, J. A simple synthetic route of N-doped mesoporous carbon derived from casein extracted with cobalt ions for high rate performance supercapacitors. Electrochim. Acta 2017, 250, 16-24. [CrossRef]

29. Hameed, B.; Ahmad, A. Batch adsorption of methylene blue from aqueous solution by garlic peel, an agricultural waste biomass. J. Hazardous Mat. 2009, 164, 870-875. [CrossRef]

30. Choi, H.-D.; Cho, J.-M.; Baek, K.; Yang, J.-S.; Lee, J.-Y. Influence of cationic surfactant on adsorption of Cr(VI) onto activated carbon. J. Hazardous Mat. 2009, 161, 1565-1568. [CrossRef]

31. Zhang, Y.; Xu, M.; Li, H.; Ge, H.; Bian, Z. The enhanced photoreduction of $\mathrm{Cr}(\mathrm{VI})$ to $\mathrm{Cr}(\mathrm{III})$ using carbon dots coupled TiO 2 mesocrystals. Appl. Catal. B Environ. 2018, 226, 213-219. [CrossRef]

32. Li, H.; Li, Y.; Chen, Y.; Yin, M.; Jia, T.; He, S.; Deng, Q.; Wang, S. Carbon Tube Clusters with Nanometer Walls Thickness, Micrometer Diameter from Biomass, and Its Adsorption Property as Bioadsorbent. ACS Sustain. Chem. Eng. 2018, 7, 858-866. [CrossRef]

33. El-Nagar, G.A.; Hassan, M.A.; Fetyan, A.; Kayarkatte, M.K.; Lauermann, I.; Roth, C. A promising N-doped carbon-metal oxide hybrid electrocatalyst derived from crustacean's shells: Oxygen reduction and oxygen evolution. Appl. Catal. B Environ. 2017, 214, 137-147. [CrossRef]

34. Sun, J.T.; Zhang, Z.P.; Ji, J.; Dou, M.L.; Wang, F. Removal of Cr(VI) from wastewater via adsorption with high-specific-surface-area nitrogen-doped hierarchical porous carbon derived from silkworm cocoon. Appl. Surf. Sci. 2017, 405, 372-379. [CrossRef]

35. Covelo, E.; Andrade, M.L.; Vega, F. Heavy metal adsorption by humic umbrisols: selectivity sequences and competitive sorption kinetics. J. Colloid Interface Sci. 2004, 280, 1-8. [CrossRef] [PubMed]

36. Mohan, D.; Rajput, S.; Singh, V.K.; Steele, P.H.; Pittman, C.U., Jr. Modeling and evaluation of chromium remediation from water using low cost bio-char, a green adsorbent. J. Hazardous Mat. 2011, 188, 319-333. [CrossRef]

37. Chu, Y.; Gu, L.; Qu, K.G.; Zhang, Y.; Zhao, J.S.; Xie, Y. The synthesis of phenanthroline and bipyridine based ligand for the preparation of $\mathrm{Fe}-\mathrm{Nx} / \mathrm{C}$ type electrocatalyst for oxygen reduction. Int. J. Hydrogen. Energ. 2018, 43, 21810-21823. [CrossRef]

38. Sen, T.K.; Afroze, S.; Ang, H.M. Equilibrium, Kinetics and Mechanism of Removal of Methylene Blue from Aqueous Solution by Adsorption onto Pine Cone Biomass of Pinus radiata. Water Air Soil Pollut. 2010, 218, 499-515. [CrossRef] 
39. Li, L.-L.; Feng, X.-Q.; Han, R.-P.; Zang, S.-Q.; Yang, G. Cr(VI) removal via anion exchange on a silver-triazolate MOF. J. Hazardous Mat. 2017, 321, 622-628. [CrossRef] [PubMed]

40. Li, D.; Li, J.; Jin, Q.; Ren, Z.; Sun, Y.; Zhang, R.; Zhai, Y.; Liu, Y. Photocatalytic reduction of Cr (VI) on nano-sized red phosphorus under visible light irradiation. J. Colloid Interface Sci. 2019, 537, $256-261$. [CrossRef] [PubMed]

41. Bai, Y.-N.; Lu, Y.-Z.; Shen, N.; Lau, T.-C.; Zeng, R.J. Investigation of Cr(VI) reduction potential and mechanism by Caldicellulosiruptor saccharolyticus under glucose fermentation condition. J. Hazardous Mat. 2018, 344, 585-592. [CrossRef] [PubMed]

42. Zhao, R.; Li, X.; Sun, B.; Ji, H.; Wang, C. Diethylenetriamine-assisted synthesis of amino-rich hydrothermal carbon-coated electrospun polyacrylonitrile fiber adsorbents for the removal of $\mathrm{Cr}(\mathrm{VI})$ and 2,4-dichlorophenoxyacetic acid. J Colloid Interface Sci. 2017, 487, 297-309. [CrossRef]

43. Zhu, K.; Chen, C.; Xu, H.; Gao, Y.; Tan, X.; Alsaedi, A.; Hayat, T. Cr(VI) Reduction and Immobilization by Core-Double-Shell Structured Magnetic Polydopamine@Zeolitic Idazolate Frameworks-8 Microspheres. ACS Sustain. Chem. Eng. 2017, 5, 6795-6802. [CrossRef]

44. Zhao, Y.; Wang, J.; Ma, C.; Li, Y. Cr $2 \mathrm{O} 3$ ultrasmall nanoparticles filled carbon nanocapsules deriving from $\mathrm{Cr}(\mathrm{VI})$ for enhanced lithium storage. Chem. Phys. Lett. 2018, 704, 31-36. [CrossRef]

45. Gong, K.; Hu, Q.; Yao, L.; Li, M.; Sun, D.; Shao, Q.; Qiu, B.; Guo, Z. Ultrasonic Pretreated Sludge Derived Stable Magnetic Active Carbon for Cr(VI) Removal from Wastewater. ACS Sustain. Chem. Eng. 2018, 6, 7283-7291. [CrossRef]

46. Song, B.; Wang, T.; Wang, L.; Liu, H.; Mai, X.; Wang, X.; Wang, N.; Huang, Y.; Ma, Y.; Lu, Y. Interfacially reinforced carbon fiber/epoxy composite laminates via in-situ synthesized graphitic carbon nitride (g-C3N4). Compos. Part B Eng. 2019, 158, 259-268. [CrossRef]

47. Gong, K.; Hu, Q.; Xiao, Y.; Cheng, X.; Liu, H.; Wang, N.; Qiu, B.; Guo, Z. Triple layered core-shell ZVI@carbon@polyaniline composite enhanced electron utilization in $\mathrm{Cr}(\mathrm{vi})$ reduction. J. Mat. Chem. A 2018, 6, 11119-11128. [CrossRef] 